\title{
Unilateral Complete Duplication of Ectopic, Refluxing Ureters: A Rarest Entity
}

\author{
Vilas P. Sabale ${ }^{a}$, Vikram Satav ${ }^{a}$, Bhupender Kadyanª, , Sharad P. Kankalia ${ }^{a}$, Deepak Manea, \\ Abhirudra Mulay ${ }^{\mathrm{a}}$
}

\begin{abstract}
A ureter that opens at a site distal to the posterolateral aspect of the trigone is known as ectopic ureter. Commonly with complete duplication, upper moiety ureter can be ectopic. A 7-year-old boy presented with dull pain in right flank with repeated episodes of urinary tract infection. Clinically, no abnormality was detected. Ultrasonography revealed right gross hydronephrosis with hydroureter up to ureterovesical junction. Micturating cystourethrogram suggested grade $\mathrm{V}$ reflux in both ureters of complete duplication. Right kidney had $20 \%$ split function (glomerular filtration rate: $18 \mathrm{~mL} /$ minute). Cystoscopy revealed both the ureteric orifice in small prostatic urethral diverticulum. Common sheath ureteric reimplantation was done by PolitanoLeadbetter technique. Ectopic ureteral orifice is not uncommon, especially with complete duplication. But complete duplication opening in ectopic position (prostatic urethra) with high grade reflux in both the ureters is extremely uncommon entity. No similar case report could be seen in available literature, making this a unique case.
\end{abstract}

Keywords: Ectopic; Refluxing; Ureter

\section{Introduction}

A ureter that opens at a site distal to the posterolateral aspect of the trigone is known as ectopic ureter [1]. Commonly with complete duplication, upper moiety ureter can be ectopic. We present a case of complete duplication with both ureteric opening in prostatic urethra with grade $\mathrm{V}$ reflux.

\section{Case Report}

A 7-year-old boy presented with dull pain in right flank with

Manuscript accepted for publication February 06, 2015

aDepartment of Urology, Dr. D.Y. Patil Medical College, Pimpri, Pune, India

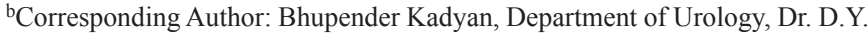
Patil Medical College, Pimpri, Pune 411018, Maharashtra, India.

Email: drkadyan@yahoo.com

doi: http://dx.doi.org/10.14740/wjnu195w repeated episodes of urinary tract infection. Clinically, no abnormality was detected. Ultrasonography revealed right gross hydronephrosis with hydroureter up to ureterovesical junction. Micturating cystourethrogram suggested grade $\mathrm{V}$ reflux in both ureters of complete duplication (Fig. 1). Right kidney had 20\% split function (glomerular filtration rate: $18 \mathrm{~mL} / \mathrm{min}$ ). Cystoscopy revealed both the ureteric orifice in small prostatic urethral diverticulum (Fig. 2). Common sheath ureteric reimplantation was done by Politano-Leadbetter technique with double J stenting (Fig. 3, 4).

\section{Discussion}

The theory behind the ureteral ectopia with or without ureterocele rests in uretero-trigonal and renal development involving the common nephric duct, ureteral budding, ureterometanephric interaction and bladder and trigone development. Ectopic ureters results due to abnormal timing or location of the primary ureteral budding from mesonephric duct (MND) or abnormalities at the stage of ureter [2].

Chawalle postulated that the distal ureter expansion is produced by the failure of rupture of a distal membrane at the ureteral orifice (Chawalle membrane) [3].

During development, lower bud, which is associated with

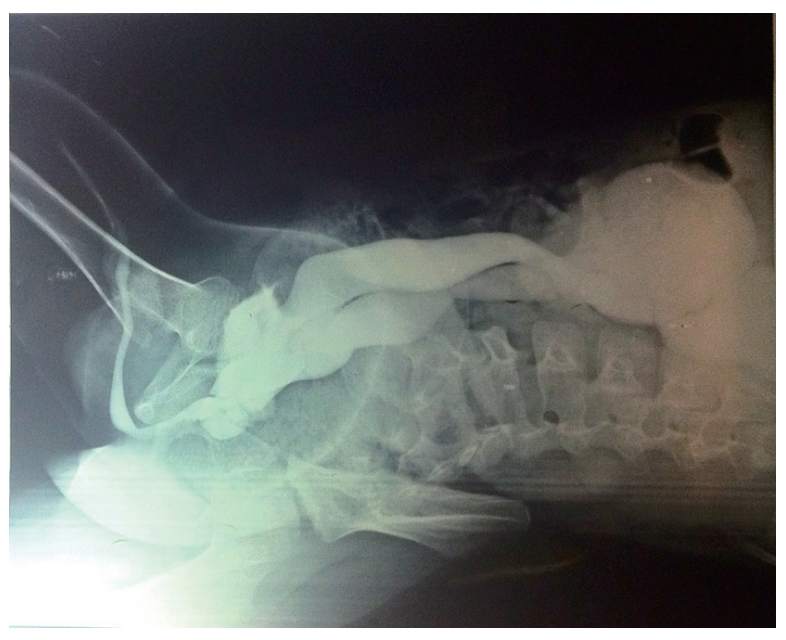

Figure 1. Micturating cystourethrogram. 


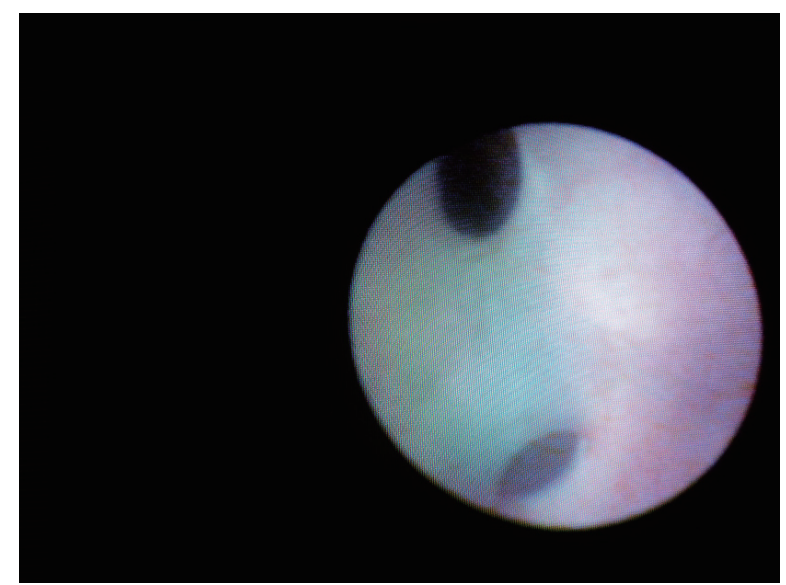

Figure 2. Cystoscopy revealed both the ureteric orifice in small prostatic urethral diverticulum.

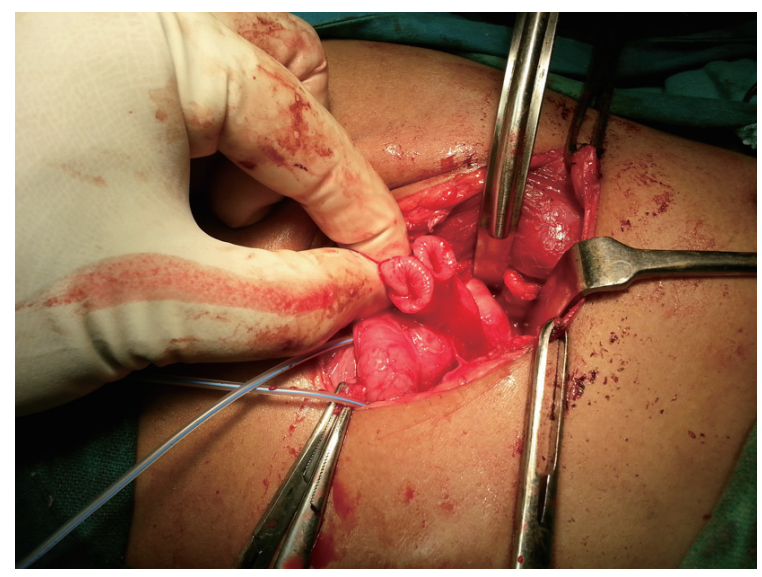

Figure 3. Intraoperative findings showing both the moiety.

the lower pole of the kidney is incorporated first and migrates more laterally. The upper pole ureter gets incorporated later and therefore lies closer to the bladder neck. The WeigertMeyer rule describes the inverse relationship of the duplex ureteral orifices, in which the ectopic ureter or ureterocele associated with the upper pole is caudal to the lower pole ureteral orifice [4].

Prenatal ultrasonography remains the diagnostic modality in majority of the cases even if the specific diagnosis is not made. Typical findings of an upper pole "cyst" in a fetus should be interpreted as being upper pole hydronephrosis until proven otherwise. Voiding cystourethrogram (VCUG) provides the most definitive evaluation of the bladder, distal ureters and urethra and should be a part of the management.

Intravenous pyelogram (IVP) offers adequate anatomic delineation and also functional information. Functional renal assessment should be a part of initial workup, dimercaptosuccinic acid (DMSA) being the modality of choice. Finally, endoscopic evaluation should be performed thoroughly before any intervention.

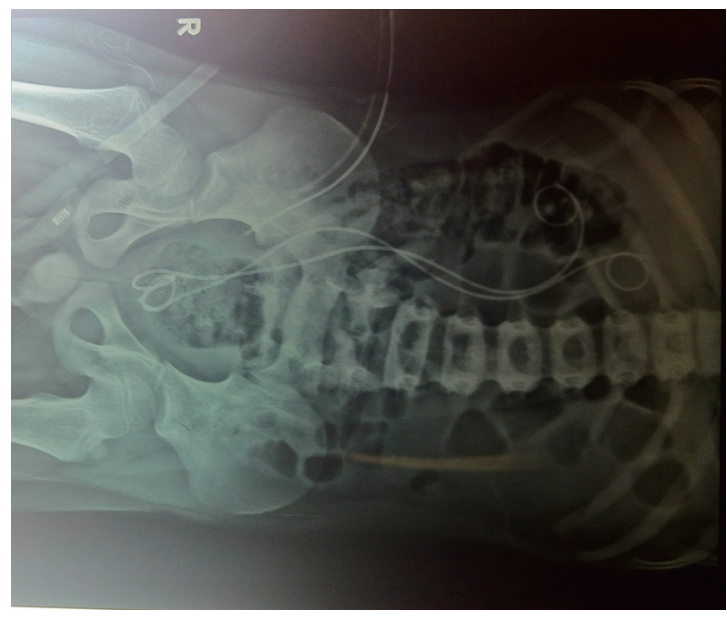

Figure 4. Post-operative X-ray.

\section{Conclusion}

Ectopic ureteral orifice is not uncommon, especially with complete duplication. But complete duplication opening in ectopic position (prostatic urethra) with high grade reflux in both the ureters is extremely uncommon entity. No similar case report could be seen in available literature, making this a unique case.

\section{Acknowledgement}

Nil.

\section{Source(s) of Support}

Nil.

\section{Conflicts of Interest}

Nil.

\section{References}

1. Kesavan P, Ramakrishnan MS, Fowler R. Ectopia in unduplicated ureters in children. Br J Urol. 1977;49(6):481493.

2. Redman JF, Lightfoot ML, Reddy PP. Bilateral single ureteral ectopia in a boy. Urology. 2002;60(3):514.

3. Chawalle R. The process of formation of cystic dilatation of vesical end of the ureter and of diverticula at the ureteral intravenous pyelography (IVP) is the gold standard in ostium. Urol Cutan Rev. 1927;31.

4. Schulman CC. The single ectopic ureter. Eur Urol. 1976;2(2):64-69. 